\title{
Adolescentes Infratores: Rede Social e Funcionamento Familiar
}

\author{
Adolescent Transgressors: Social Network and Family Functioning
}

\author{
Bianca de Moraes Branco ${ }^{*} a$, Adriana Wagner ${ }^{b} \&$ Karina Adriani Demarchi $^{b}$ \\ ${ }^{a}$ Universidade Federal da Bahia, Salvador, Brasil \\ ${ }^{b}$ Pontifícia Universidade Católica de Rio Grande do Sul, Porto Alegre, Brasil
}

\begin{abstract}
Resumo
O objetivo desse estudo é identificar as características da rede social dos internos da Fase-RS que cumprem medida de ICPAE (interno com possibilidade de atividade externa). Também caracterizar suas famílias, quanto aos aspectos sócio-bio-demográficos e à percepção do funcionamento familiar por esses adolescentes. Foram investigados cinco adolescentes que tiveram progressão para ICPAE, utilizando-se a metodologia de Estudo de Caso, através da confecção do mapa da rede social e da escala GARF (Global Assessment of Relational Functioning Scale) para avaliação do funcionamento familiar. Nenhum dos cinco adolescentes avaliados preencheu o quadrante trabalho/escola da rede social. Dos cinco adolescentes, três preencheram apenas os quadrantes família e amigos. O total de membros e instituições incluídas no mapa da rede social variou entre seis e doze. As notas de funcionamento familiar foram baixas.

Palavras-chave: Adolescente; família; infrator; rede social.
\end{abstract}

\begin{abstract}
The aim of this studys is to identify the characteristics of the adolescents as well as their familys social network, regarding socio-bio-demographic aspects and the interns' perception of their familys functioning. The participants were five adolescents in a State institution (FASE-RS) who were also allowed to have external activities. A case study method was used through the making of a social network map and the family's functioning was measured using the global assessment of relational functioning scale (GARF). None of the five adolescents assessed used the work/school quadrant of social network. Three of them only filled the family and friends' quadrants. The total members and institutions included in the social network map varied between six and twelve. The scores on family functioning were low.

Keywords: Adolescent; family; social network; transgressor.
\end{abstract}

A adolescência é uma fase caracterizada pela transição em vários domínios do desenvolvimento, seja biológico, cognitivo ou social; por conflitos internos e lutos que exigem do adolescente a elaboração e a ressignificação de sua identidade, imagem corporal, relação com a família e com a sociedade (Diretoria Sócio-Educativa da Fundação Estadual do Bem Estar do Menor/RS, 2002).

Além de toda conflitiva interna própria desta fase, estudos têm atentado para os determinantes situacionais da conduta destes jovens e, dentre esses, o vigente estudo visa elucidar mais especificamente a rede social e, inclusa nela, a família do adolescente infrator. A adolescência é um período crítico no desenvolvimento das relações sociais e, neste período, os vínculos deixam de ser centrados na família. Normalmente, deslocam-se para a relação com os pares, sejam colegas, amigos ou parceiros românticos com os quais o jovem se sente apoiado. Eles desenvolvem habilidades sociais através dessas relações, onde compar-

\footnotetext{
* Endereço para correspondência: Universidade Federal da Bahia, Av. Reitor Miguel Calmon, s/n, Vale do Canela, Salvador, BA, 40110-905. Tel.: (71) 3283 8850. E-mail: bmbranco@yahoo.com.br
}

tilham experiências, emoções e conhecimentos. Entretanto, o desenvolvimento da adolescência saudável requer um equilíbrio entre o apoio da família, associações formais (como professores) e apoios informais, tais como amigos e pares da mesma idade (Johnson, Whitbeck \& Hoyt, 2005).

A literatura especializada registra que algumas características familiares têm sido consideradas preditoras de conduta pró-social ou protetora dos atos infracionais dos jovens. São elas: a estrutura hierárquica definida (Valdés et al., 1997), a boa qualidade da relação entre os pais (Markiewicz, Doyle \& Brendgen, 2001), o estabelecimento de um padrão de apego seguro pelo jovem (Laible, Carlo \& Roesch, 2004), a boa qualidade de comunicação do jovem com os pais e entre eles (Valdés et al., 1997), bem como menos atitudes autoritárias pelos progenitores (Caputo, 2004; Stouthamer-Loeber, Wei, Loeber \& Masten, 2004).

No entanto, a importância da rede social, além da família, desses jovens, neste comportamento, também tem sido evidenciada em alguns estudos. Nessa rede, está comprovada a importância da influência dos pares na prática do ato infracional (Caputo, 2004; Ceolin, 2003; Davis, Tang \& Ko, 2004; Stouthamer-Loeber et al., 2004; Windle \& Mason, 2004). 
Também parece claro que a delinqüência está imbricada com aspectos relativos à baixa escolaridade (Ceolin, 2003) e ao uso de drogas (Husler, Panchere \& Werlen, 2005; Stouthamer-Loeber et al., 2004; Windle \& Mason, 2004). Quanto à importância da rede social, encontrou-se que estar empregado ou na escola, no início da idade adulta, são fatores protetores da recaída no ato infracional (Stouthamer-Loeber et al., 2004).

No Rio Grande do Sul, os adolescentes infratores são julgados por um juiz da Infância e da Adolescência e podem ser condenados à medida sócio-educativa, a ser cumprida na Fundação de Atendimento Sócio-Educativo (Fase). O programa da Fase está organizado em dois eixos: o processo de execução de internação e o de semiliberdade. Dentro da execução da internação, o adolescente pode cumprir a medida de ICPAE - interno com possibilidade de atividade externa ou de ISPAE - interno sem possibilidade de atividade externa.

Partindo, então, desses pressupostos empíricos e refletindo sobre a prática exercida para o cumprimento da medida sócio-educativa (ICPAE), o objetivo deste estudo é identificar as características da rede social dos adolescentes que cumprem a medida de internação - ICPAE, avaliar esta medida e caracterizar as famílias desses internos, quanto aos aspectos sócio-bio-demográficos e quanto à percepção destes jovens do funcionamento de sua família.

\section{Método}

O método utilizado nesta pesquisa é o Estudo de Caso Individual, proposto por Stake (2005), que busca, especialmente, o que pode ser aprendido a partir do caso singular. Portanto foram feitas articulações entre a construção dos Mapas da Rede Social, os dados de avaliação da medida de ICPAE e do funcionamento familiar de cada sujeito estudado, de forma que esses instrumentos se constituíssem em óticas diferentes e complementares do mesmo objeto.

\section{Participantes}

Foram estudados cinco adolescentes infratores que estavam cumprindo algum período dos dois primeiros meses da medida de ICPAE na Fase-RS e que aceitaram participar da pesquisa.

\section{Instrumentos}

Foram utilizados o Instrumento de Avaliação da Medida de ICPAE, versão do adolescente e da monitoria/equipe técnica, o Mapa da Rede Social (Sluzki, 1996), a entrevista semi-estruturada (Meneses, 2004) e a Escala de Avaliação Global do Funcionamento Interacional - GARF (Kaslow, 1996).

A GARF avaliou essencialmente a satisfação das necessidades dos sujeitos, a flexibilidade de papéis, os conflitos, a hierarquia, o reconhecimento das características pes- soais dos membros da família e a expressão de sentimentos. A GARF é uma escala diagnóstica do funcionamento familiar consagrada na literatura internacional e validada para o uso em nosso meio (Falceto, Busnello \& Bozzetti, 2000). Os escores da GARF estão distribuídos em quatro categorias: de 81 a 100 - funcionamento familiar bom, de 61 a 80 - padrão de relacionamento familiar de alguma forma insatisfatório, 41 a 60 - família com predomínio de relações insatisfatórias, 21 a 40 -família claramente disfuncional (Tucci, Kerr-Correa \& Dalben, 2001).

O Mapa da Rede Social tem sido utilizado em várias pesquisas (Dabas, 1995; Sluzki, 1996), mostrando-se útil para a compreensão da estrutura e funcionamento das redes sociais. Este mapa consiste em três círculos concêntricos divididos em quatro quadrantes: família, amigos, escola-trabalho e comunidade. O núcleo do círculo representa o sujeito, o primeiro círculo e menor, indica a proximidade e a importância que o adolescente dá aos sistemas ali existentes; o segundo círculo se constitui por pessoas que têm menor proximidade e importância para ele; finalmente, no terceiro círculo, se colocam as pessoas que compartilham com o adolescente de forma mais distante. Foram utilizados adesivos, cada um representando um indivíduo ou instituição, já em formatos redondos (para as mulheres) e quadrados (para os homens) ou de triângulos (instituições).

A Entrevista Semi-estruturada foi proposta por Meneses (2004), com questões que visam esclarecer categorias específicas da rede social. Para a dimensão estrutural, as categorias são o tamanho da rede, a densidade, a distribuição, a dispersão e a homogeneidade. Para a dimensão funcional, são a companhia social, o apoio emocional, o guia cognitivo, a regulação social, a ajuda material e de serviços e o acesso a novos contatos. As perguntas eram tais como: O que você acha do número de pessoas que compõem tua rede social?(avaliação do tamanho); Qual a tua opinião sobre a forma como as pessoas estão distribuídas nos diferentes espaços (quadrantes)? (avaliação da distribuição); O quanto as pessoas que compóem tua rede social se parecem contigo?(avaliação da homogeneidade), etc. Com relação à avaliação da dimensão funcional e regulação social, perguntamos: Quando você tem vontade de sair, a quem convida? (companhia social); ou quando tu precisas recorrer a alguém que te ajude a colocar limites, a quem recorres? (regulação social).

A Avaliação da Medida de ICPAE foi desenvolvida para esta pesquisa e considera como variáveis os atrasos no retorno, fuga, necessidade de medidas disciplinares, uso de drogas, reincidência no ato infracional, o comprometimento com a escola e o comprometimento com atividades laborais. Essas variáveis foram consideradas significativas por uma pesquisa do programa de inserção comunitária e acompanhamento de egressos da FEBEM/RS, elaborado em 2001. (Diretoria Sócio-Educativa da Fundação Estadual do Bem Estar do Menor/RS, 2002). A avaliação das variáveis foram feita a partir de tais perguntas: 
Tens te atrasado no retorno de casa para a FASE?, avaliando atrasos; ou tens falhado com a escola em termos de horário, freqüência e notas?, para avaliar o comprometimento escolar, etc. Conforme a resposta, o jovem poderia receber nota 1 (freqüentemente), 2 (às vezes), 3 (raramente) ou 4 (nunca) em cada pergunta. A partir da soma das notas obtidas em cada uma das oito questões, obtém-se a nota final deste instrumento, que pode variar entre o8 e 32, sendo que 32 é a melhor nota de cumprimento da medida e 08, a pior. Para fins de padronização, para este estudo, estipulou-se que as notas de 8 a 16 seriam ruins, de 17 a 24, limítrofes, e de 25 a 32 , boas.

\section{Procedimentos}

A pesquisa foi autorizada pela presidência da Fase-RS, pelo Juizado da Infância e da Juventude e aprovada pelo Comitê de Ética da Pontifícia Universidade Católica do Rio Grande do Sul (PUC-RS). Os dados foram coletados em uma sala da própria Fase, e os adolescentes foram orientados a serem sinceros e tranqüilizados quanto ao sigilo desses dados e quanto a não utilização desses pelo juiz.

As perguntas do Instrumento de Caracterização do Núcleo Familiar dos Adolescentes ICPAE foram feitas verbalmente ao jovem. Em seguida, a partir de uma entrevista semi-estruturada individual com o adolescente, feita por entrevistador habilitado, o funcionamento familiar recebeu uma nota, conforme a GARF.

Com vistas à avaliação da rede social, os adolescentes foram convidados a criarem a sua rede social, sendo esta etapa gravada em fitas de áudio. Eles tiveram à disposição os adesivos e o mapa, proposto por Sluzki (1996), e foram questionados com as seguintes perguntas: Quem são as pessoas importantes na tua vida?, Com quem podes contar?, Qual é o papel desta pessoa na tua vida?. À medida que o adolescente foi respondendo estas perguntas, ele foi convidado a representar graficamente, no mapa, cada indivíduo citado, através dos adesivos. Isso concluído, foram feitas as perguntas do questionário proposto por Meneses (2004), de forma a enriquecer o mapa e torná-lo mais fidedigno. A partir desta entrevista semi-estruturada, freqüentemente o jovem se lembrava de outras pessoas ou instituições significativas para ele, e então lhe era questionado se gostaria de acrescentar este indivíduo/instituição no mapa.

O instrumento de Avaliação da Medida de ICPAE foi aplicado levando em consideração, além da percepção do próprio interno, a de um representante da equipe técnica e outro da monitoria. Esses representantes foram escolhidos conforme a sua disponibilidade e foram priorizados aqueles que afirmavam conhecer melhor o adolescente. A equipe técnica é uma equipe formada por psicólogos, assistentes sociais e educadores e é responsável pela realização dos relatórios avaliativos dos adolescentes a cada audiência, bem como pelo contato com as famílias, com as escolas e pelas visitas domiciliares. Os monitores são funcionários que convivem no dia-a-dia com os jovens, colocando limites e estabelecendo medidas disciplinares. Es- sas três visões foram levadas em consideração, tendo em vista que a visão única do adolescente seria de pouca confiabilidade, na medida em que eles poderiam temer que estas revelações viessem a julgamento, mesmo tendo sido orientados do contrário.

\section{Resultados}

Os dados da pesquisa serão apresentados caso a caso, na seguinte ordem: resumo da história do adolescente, nota GARF do funcionamento familiar, nota quanto ao sucesso da medida de ICPAE e o Mapa da Rede Social.

\section{Adolescente Eduardo - A Ovelha Negra}

Ele tem 18 anos e cursa o $1^{\circ}$ ano do ensino médio. Teve várias repetências, segundo ele, devido a constantes mudanças de cidade. Afirma que começou a traficar aos 15 anos, por curiosidade e adrenalina.

A nota GARF de avaliação do funcionamento familiar ficou em 55, o que significa que a família tem momentos de satisfação, mas com predomínio de relações insatisfatórias e de comunicação inviabilizada por conflitos não resolvidos. A tomada de decisões é só intermitentemente competente e efetiva. Apesar de haver algum calor e apoio entre os membros, há o sentimento, em Eduardo, de ser o preterido na família.

Eduardo avaliou sua medida de ICPAE com nota 25, a técnica, com nota 32 e a monitoria, com nota 26. Considerando que a melhor nota seria 32, ele obteve o resultado bom em todas as avaliações.

O mapa da rede social do adolescente Eduardo. As duas primeiras pessoas escolhidas como mais importantes e com quem ele mais poderia contar foram a mãe e o irmão F. A $3^{\mathrm{a}}$ pessoa foi um amigo, que mais tarde se revelou como primo também, mas que foi colocado no quadrante amigos, o J. Este amigo tem idade próxima a dele, cresceram juntos e chegaram a praticar roubo juntos, mas, segundo Eduardo, apenas uma vez, «quando eu convidei».

Depois de inserir essas três pessoas ele, no momento da Entrevista Semi-estruturada (Meneses, 2004), acrescentou mais três pessoas. A namorada entrou no quadrante família, quando lhe foi perguntado com qual pessoa ele teria mais proximidade física (quesito dispersão). Quando questionado quem o ajudava a se controlar e a ter mais limite (quesito regulação social), ele respondeu acrescentando a psiquiatra da Fase no quadrante amigos. Quando perguntado sobre se teria alguém de um contexto religioso, no quesito acesso a novos contatos ele lembrou da tia, segundo ele, muito religiosa, e a acrescentou no quadrante família.

O tom da entrevista foi de desconfiança e de sentimento de diferença em relação aos demais membros familiares, parecendo sentir-se um ovelha negra. 


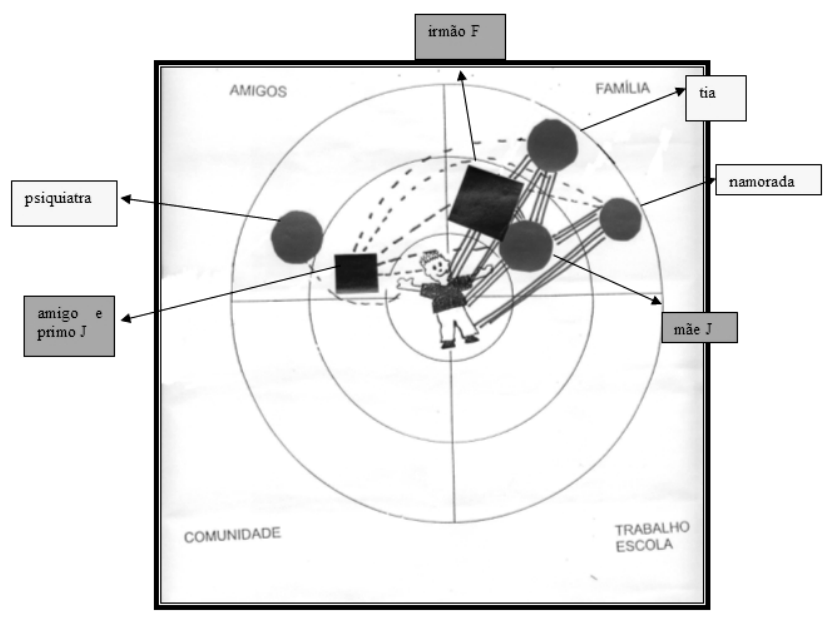

Figura 1. Mapa da rede social de Eduardo.

Nota. As flechas apontam para os quadrados cinza, onde constam os lembrados espontaneamente, e para os quadrados brancos, onde constam os lembrados a partir da entrevista sobre o mapa.

\section{Adolescente Tadeu - O Abrigado}

Tadeu tem 18 anos e cursa o $1^{\circ}$ ano do $2^{\circ}$ grau. Seus pais se separaram há mais de 10 anos. O pai bebia e era muito agressivo, tanto com a esposa, quanto com seus filhos. Aos 14 anos, o jovem teve de cumprir programa de serviço à comunidade (PSC), em liberdade assistida (LA), por porte ilegal de arma. Aos 15 anos, Tadeu foi encaminhado para um abrigo, através da Justiça, por encontrarse em situação de conflitos agressivos com seu pai e de risco de morte na comunidade (tinha sido acusado de queimar uma casa). No entanto, enquanto no abrigo, não ia ao trabalho, gazeava aulas, não visitava familiares, fugia, usava drogas.

A nota GARF do funcionamento familiar foi 30, o que significa que a família é claramente disfuncional, com presença de poder muito negligente, contato afetivo raramente satisfatório e conflitos não resolvidos.

O Tadeu avaliou sua medida de ICPAE com nota 26. Já a equipe técnica deu nota 27 , e a monitoria, nota 21 . Portanto, ele e a equipe técnica consideraram que ele estava tendo uma boa medida, já a monitoria, a considerou limítrofe.

O mapa da rede social do adolescente Tadeu. Quanto ao mapa da rede social, também este adolescente não inseriu nenhum membro ou instituição nos quadrantes trabalho, escola e comunidade. Primeiramente, Tadeu o construiu considerando apenas a namorada e a mãe, ambas colocadas no quadrante família.

Com a Entrevista Semi-estruturada, surgiram os demais integrantes. Três monitoras foram inseridas no quadrante amigos, quando perguntado quem o ajudava a se controlar, colocando limites, isto é, quesito regulação social. A cunhada V. foi incluída no mapa no quadrante família quando respondeu à questão de quem dá a ajuda material. $\mathrm{O}$ irmão da igreja foi incluído no mapa na intersecção do quadrante família com amigos, quando ele foi questionado diretamente sobre a existência de algum representante religioso que ele sentisse que poderia contar como importante para ele.

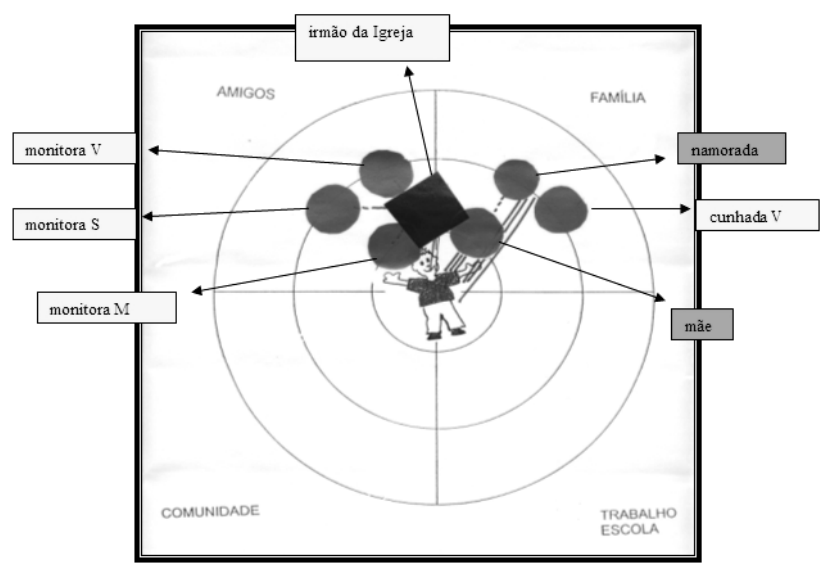

Figura 2. Mapa da rede social de Tadeu.

Nota. As flechas apontam para os quadrados cinza, onde constam os lembrados espontaneamente, e para os quadrados brancos, onde constam os lembrados a partir da entrevista sobre o mapa.

\section{Adolescente Guilherme - O Solitário}

Guilherme tem 19 anos e cursa a $8^{\text {a }}$ série. Afirma que, aos 9 anos, começou a fumar cigarros e canabis e, depois, a fumar crack e cheirar loló. Com 14-15 anos, pôs-se a roubar para comprar drogas e besteiras para o videogame. Os pais teriam descoberto o uso de drogas quando Guilherme estava ainda com 09-10 anos, e a reação dos pais foi de agressividade para com o jovem. Ele recebeu medida de PSC, em Janeiro de 2005, por assalto à mão armada, mas, não cumprindo a medida, foi privado de liberdade.

O funcionamento familiar de Guilherme, avaliado pela GARF, recebeu nota 21, isto é, uma família claramente disfuncional, onde há poucas rotinas interacionais, a comunicação é comprometida em função de mal entendidos, as responsabilidades pessoais não são reciprocamente aceitas e reconhecidas e pouca atenção é dada às necessidades emocionais dos outros.

$\mathrm{Na}$ avaliação da medida de ICPAE, Guilherme se deu nota 28 , enquanto a monitoria e a equipe técnica deram nota 29, o que significa um bom cumprimento de medida e uma coerência entre os avaliadores e o sujeito.

O mapa da rede social do adolescente Guilherme. Guilherme só inseriu membros da família em seu mapa, tendo sido o único adolescente a não preencher o quadrante amigos. A pessoa mais importante para ele é sua mãe. A $2^{\mathrm{a}}$ pessoa mais importante, sua meio-irmã C. Depois, ele considera o meio-irmão, os dois irmãos e o pai em um mesmo nível de importância. Ele diz que o meio-irmão A. poderia ajudálo mais, já que não pratica atos contra a lei, como os outros dois, mas sente os irmãos D. e J. mais próximos e mais parecidos com ele.

Quanto às respostas à Entrevista Semi-estruturada, as categorias apoio emocional, conselhos, regulação social, ajuda material e acesso a novos contatos remeteram sempre novamente à família, mais especificamente à mãe e aos 
irmãos. Ele disse que sentia falta do trabalho no mapa. Mostrou-se ressentido com aqueles que julgava serem seus amigos, mas que desapareceram desde que foi preso.

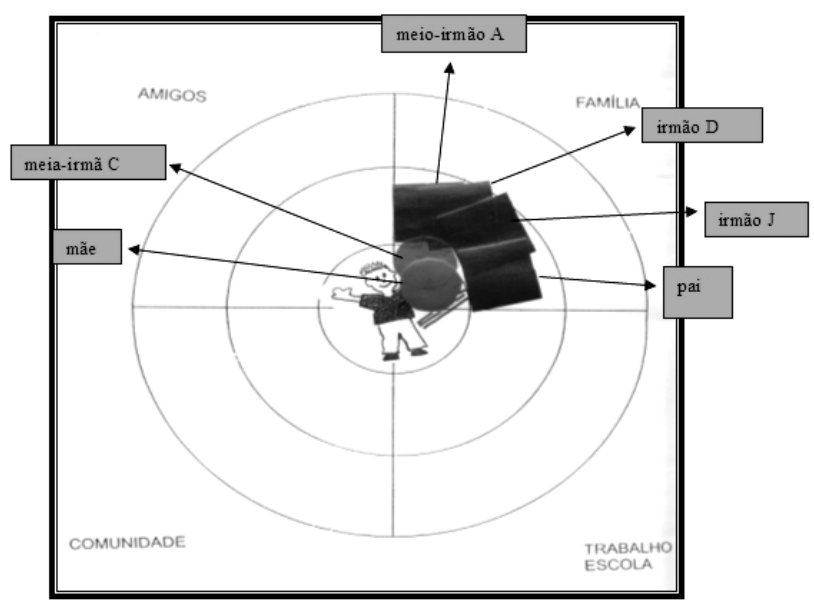

Figura 3. Mapa da rede social de Guilherme.

Nota. As flechas apontam para os quadrados cinza, onde constam os lembrados espontaneamente. Ele não acrescentou ninguém a partir da entrevista.

\section{Adolescente Júnior - Muitos Amigos}

Júnior tem 18 anos e cursa o $1^{\circ}$ ano do $2^{\circ}$ grau. O adolescente afirma que está envolvido com o tráfico desde os 11 anos, mas que a mãe só teria descoberto quando ele já estava com 15 anos, quando ela o viu trazendo drogas para casa. Seu $1^{\circ}$ ingresso na Fase foi aos 16 anos, quando recebeu PSC de 24 semanas por tráfico. Retornou à Fase em 2005, por porte ilegal de arma e de entorpecentes.

A través da GARF, o funcionamento familiar recebeu nota 45, isto é, a família tem momentos de satisfação, mas há um predomínio de relações insatisfatórias e de comunicação inviabilizada por conflitos não resolvidos.

Júnior avaliou a sua medida de ICPAE com nota 30, enquanto a equipe técnica deu nota 32 , e a monitoria deu nota 21 , mostrando novamente um desempenho bom conforme ele próprio e a equipe técnica e um desempenho limítrofe, segundo a monitoria.

O mapa da rede social do adolescente Júnior. Júnior não inseriu ninguém nos quadrantes trabalho/escola e comunidade do seu mapa. Ele colocou a sua mãe como a pessoa mais importante para ele e com quem ele mais podia contar, embora a considere muito diferente, muito braba. A segunda pessoa lembrada foi a irmã D., que é quem ele considera mais parecida no jeito de ser com ele. Na seqüência, ele colocou o irmão A., a irmã F. e o padrasto, mas Júnior vê a F. como o membro familiar mais afastado de todos, tanto física quanto psicologicamente.

Os demais integrantes do mapa de Júnior só foram lembrados quando das perguntas da Entrevista Semiestruturada. Quando questionado sobre os amigos, ele se mostrou muito desconfiado e ambivalente, sem saber se poderia de fato contar com eles. Acabou colocando os amigos I., R., E., C. e o G. como as companhias sociais e a ajuda material. O papel de apoio emocional e conselheiro e serviços é exercido pela mãe. Ele não reconhece ninguém externo tendo o papel de regulação social, a não ser ele próprio. O irmão A. teria um papel de ajuda de serviço. O acesso a novos contatos se daria através da família e dos amigos.

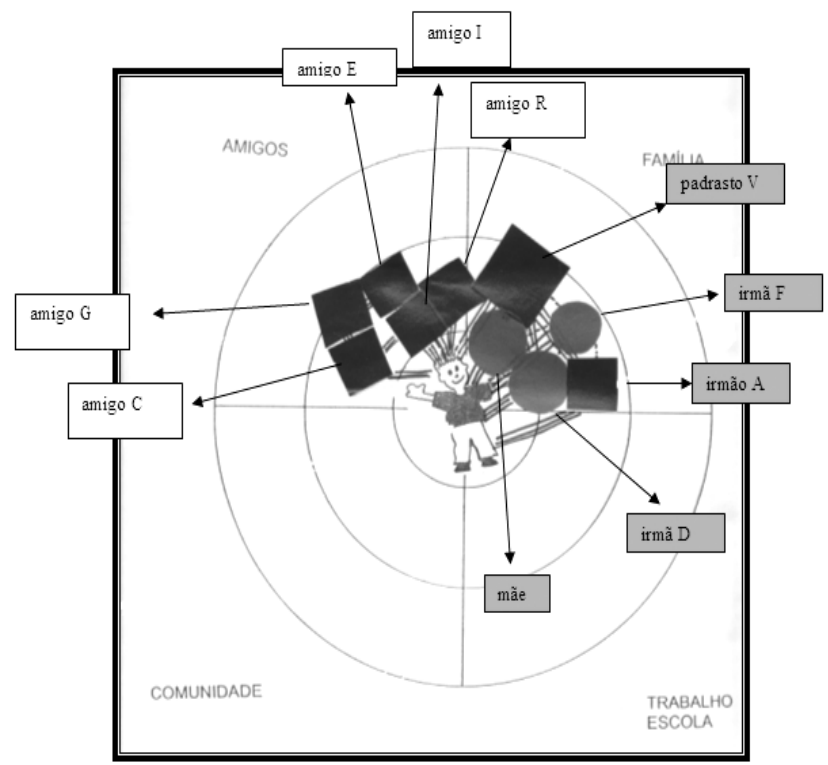

Figura 4. Mapa da rede social de Júnior

Nota. As flechas apontam para os quadrados cinza, onde constam os lembrados espontaneamente, e para os quadrados brancos, onde constam os lembrados a partir da entrevista sobre o mapa.

\section{Adolescente Bernardo - O Criticado}

Bernardo tem 18 anos e parou de estudar na $8^{\text {a }}$ série. Repetiu a $1^{\text {a }}$ série, por ser muito tímido, e a $3^{\mathrm{a}}$ série, porque não prestava atenção. Aos 8 anos, teve de interromper os estudos para trabalhar com seus pais na lavoura. Ele afirmou que, com 11-12 anos, começou a se revoltar com o pai, porque trabalhava para ajudá-lo, mas o pai se mostrava sempre insatisfeito com o que ele fazia, o criticava e não o recompensava pelo seu esforço. Teve outros trabalhos e, com 16 anos, começou a roubar. Em 2005, ingressou na Fase por roubo qualificado.

A família recebeu uma nota de funcionamento 61 , a melhor nota entre os adolescentes. Esta família, portanto, mostrou um padrão de relacionamento familiar de alguma forma insatisfatório, mas com resolução sem grandes frustrações e conflitos para os problemas e presença de relações afetivas de amor e respeito.

Bernardo avaliou sua medida de ICPAE com nota 29. A monitoria deu nota 31 e a equipe técnica, nota 32, portanto, as três notas são compatíveis com um bom cumprimento de medida.

O mapa da rede social do adolescente Bernardo. Quanto ao mapa da rede social, este foi o único adolescente que preencheu, além dos quadrantes família e amigos, o quadrante comunidade. A primeira a ser lembrada foi a mãe, seguida pela irmã A. Após, Bernardo lembrou de Deus, o colocando no quesito amigos. Depois, ele inseriu o pai, dizendo 
que apesar do que aconteceu, ele não deixa de ser meu pai. A cunhada F. veio em seguida, no quadrante família. A monitoria, pela primeira vez, foi lembrada espontaneamente e colocada no quadrante amigos. A instituição Fase foi mencionada, pela primeira vez, e colocada no quesito comunidade. Também a instituição Igreja foi inserida de forma espontânea no quesito comunidade.

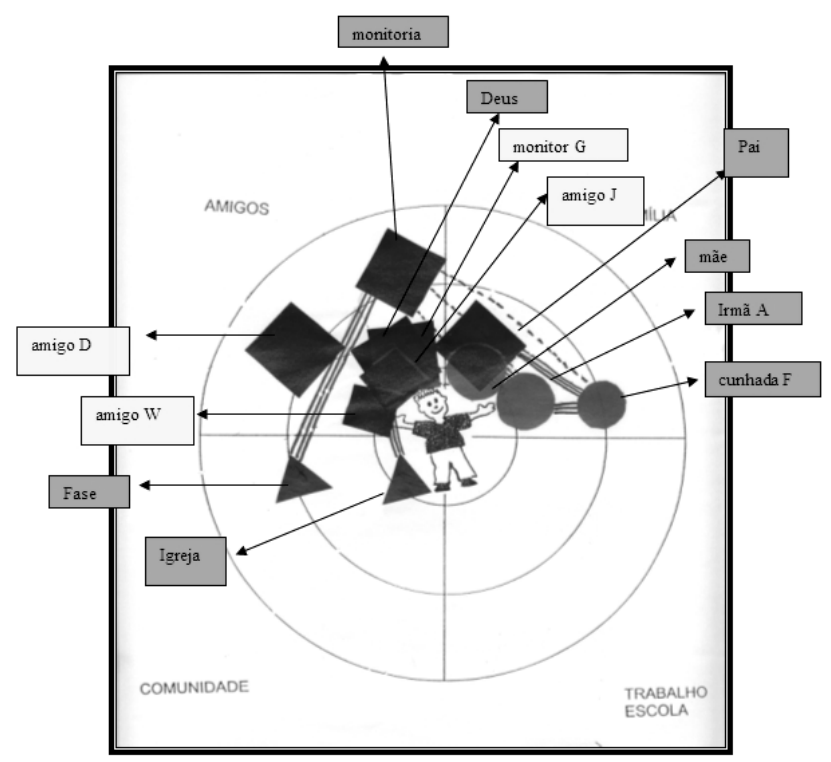

Figura 5. Mapa da rede social de Bernardo.

Nota. As flechas apontam para os quadrados cinza, onde constam os lembrados espontaneamente, e para os quadrados brancos, onde constam os lembrados a partir da entrevista sobre o mapa.

Quanto à Entrevista Semi-estruturada, no quesito dispersão, Bernardo disse ver sempre os pais, mas que gostaria de ver a irmã A. e a cunhada F. mais freqüentemente. No quesito homogeneidade, o jovem vê a família mais conformada e resignada com as dificuldades do que ele próprio. Ele se vê muito diferente do seu pai, e distante dele. Diz se identificar mais com a cunhada, por ela ouvir suas propostas e auxiliá-lo nas suas realizações. Quando questionado sobre a companhia social, ele acrescentou os amigos J. e W., que disse serem legais, mas não aprovados pela mãe, pelo fato de serem muito bagunceiros. Nos quesitos apoio emocional e conselheiro, ele lembra do monitor G., e decide colocá-lo em separado da monitoria e mais próximo dele, ainda que também no quadrante amigos. Mas, ele reconhece ter muita dificuldade em pedir apoio para alguém. Nega precisar de um regulador social externo. A ajuda material foi vista como fornecida pela mãe e a ajuda de serviço, pela cunhada. A mãe foi relembrada quando questionado sobre quem seria o acesso a novos contatos, mas também lembrou do amigo D., que o teria estimulado ao trabalho, e que foi inserido no quadrante amigos.

\section{Análise dos Casos}

A rede social tem um importante papel na compreensão, prevenção e tratamento de jovens delinqüentes (Rydelius, 2001), e não é de hoje que se considera a importância da família neste comportamento.

Portanto, avaliando os resultados com vistas a uma maior compreensão deste contexto, percebe-se que nenhum dos cinco adolescentes avaliados preencheu o quadrante trabalho e escola. Os adolescentes justificaram esses achados dizendo que, como as escolas estavam em greve, eles não estavam tendo aulas. Também afirmaram não estarem trabalhando, o que pode ser compreendido pelo fato de terem progredido para ICPAE recentemente; portanto, antes, estavam totalmente fechados na instituição, o que inviabilizava o trabalho.

A não-centralização do mapa da rede social e uma relação próxima e direta entre seus membros seriam indicadores de uma maior prontidão dessa rede, no sentido de prevenir problemas comportamentais em adolescentes (Feinberg, Riggs \& Greenberg, 2005). No entanto, dos cinco adolescentes, três preencheram somente os quadrantes família e amigos. Apenas um preencheu somente um quadrante, o família, e também apenas um preencheu três quadrantes, família, amigos e comunidade, ainda que este úl timo quadrante esvaziado em relação aos demais. O mapa desenvolvido antes das perguntas, de forma voluntária, contou com dois a oito membros. Após a aplicação do questionário proposto por Meneses (2004), o total de membros dos mapas aumentou para um intervalo entre seis e doze, o que é baixo comparando-se com os mapas da rede social obtidos por Ceolin (2003), constituídos por 12 a 32 membros. No entanto, a amostra de Ceolin foi de adolescentes infratores que cumprem PSC, sem restrição da liberdade, do que se pode hipotetizar que a restrição da liberdade acaba por reduzir o tamanho da rede social, o que parece razoável.

A família ocupou de 14 a $50 \%$ dos mapas da rede social, sendo que apenas o Guilherme destoou dos demais, colocando no mapa apenas os membros familiares. Paradoxalmente, este jovem que tanto valorizou a família, como importante e confiável, foi o que teve o mais baixo escore de funcionamento familiar (GARF 20). Este achado vai ao encontro do resultado da pesquisa de Wagner e Féres-Carneiro (2000), onde o pai que tinha uma atitude distante com relação ao filho era representado graficamente por ele de forma idealizada. Nesse caso, parece que a idealização oculta uma carência. Nessa perspectiva, vale notar que a agressividade dos pais de Guilherme parece ter uma influência de reforço em seus atos infracionais, como descrito na literatura (Caputo, 2004; Stouthamer-Loeber, Wei, Loebe \& Masten, 2004).

Também esses dados mostram como a importância da família está centrada na figura da mãe (sempre a primeira lembrada) e dos irmãos, com uma figura paterna periférica. Quanto aos irmãos, ou foram trazidos todos para o mapa, ou apenas um mais velho, que parece assumir um papel de auxiliar da mãe no cuidado dos mais novos. 
As notas de funcionamento familiar foram baixas variando de 21 a 61 . Um dos aspectos que foi avaliado através da GARF foi a expressão de sentimentos. Os adolescentes, de modo geral, falaram da dificuldade de se abrir com a família, de falar das suas dificuldades e de pedir ajuda a eles.

Praticamente todos os jovens entrevistados falaram da influência dos pares na iniciativa do ato delinqüente, bem como do ressentimento com estes amigos, que só se apresentaram enquanto parceria para uso de drogas e para a prática de atos delinqüentes, mas que sumiram quando deste momento de dificuldade, com restrição da liberdade e afastamento da família.

O cuidado de se escolher um representante da monitoria com maior convívio com o adolescente para a nota do ICPAE foi importante, pois como eles trabalham por turnos, dependendo da atividade do interno, determinado monitor poderia praticamente nunca ter visto o adolescente pesquisado. Um dado positivo é o fato da avaliação da medida de ICPAE ter sido considerada boa, de forma unânime, em três dos cinco casos. Em dois casos, ela foi considerada boa apenas pelo próprio interno e pela equipe técnica, mas limítrofe pela monitoria. Isso pode significar que, por estar mais próxima no dia-a-dia do adolescente, a monitoria tenha fornecido um dado mais fidedigno. No entanto, também pode estar evidenciando uma menor tolerância da monitoria com os adolescentes, pelo estresse a que se submete, em função do convívio continuado com os jovens, bem como pelo grande número de horas extras que cumprem. No entanto, parece preponderar o primeiro argumento, já que os monitores da Fase estão presentes em dois dos cinco mapas. Ainda que a psiquiatra possa ter sido incluída para responder a uma expectativa imaginada pelo adolescente, já que a psiquiatra é uma das pesquisadoras, os monitores não estavam incluídos diretamente na pesquisa e desenvolvem um trabalho à parte do trabalho da equipe da saúde. Além disso, é bastante comum que os adolescentes façam críticas de um segmento da casa para outro (por exemplo, critiquem a monitoria para o setor de saúde), o que torna ainda mais valioso o fato de os monitores terem sido lembrados e trazidos de forma positiva nessa pesquisa. A lembrança dos funcionários da Fase se deu uma única vez de forma voluntária, ainda que desta vez tenha sido feita de forma geral (monitoria). As lembranças de nomes específicos ocorreram quando do questionamento dos seguintes quesitos: regulação social, apoio emocional e conselheiro. Isso mostra mais claramente qual o papel que os funcionários da Fase, principalmente a monitoria e a psiquiatra, têm exercido para estes jovens.

A droga, seja pelo seu uso, seja pela sua venda, esteve presente também na vida de 4 dos 5 adolescentes, excluindo-se o Bernardo. Coincidentemente ou não, o Bernardo foi o que teve o mapa mais completo (12 membros) e com melhor distribuição (utilizando três quadrantes), e o que se sentiu mais próximo da instituição Fase e da monitoria, os citando voluntariamente.

\section{Considerações Finais}

Frente às informações levantadas nos cinco casos estudados, conclui-se quão importante é que se implantem medidas educativas e laborais mais significativas para esses internos, bem como que se desenvolvam atividades comunitárias. Essas os tornariam mais cientes do seu papel social e da repercussão da sua atitude na vida dos demais.

No entanto, essa população parece culturalmente avessa à idéia de se poder extrair real prazer dos bancos escolares ou do trabalho. Seja pela observação de outros, ou partindo de sua própria má experiência com escolas públicas deficitárias, a educação é, em geral, vista como um mal, não necessariamente indispensável. O trabalho também não lhes parece algo dignificante, uma peça chave para a autoconstrução como indivíduo, senão um meio não atraente de se conseguir dinheiro.

Para agravar a situação, as possibilidades de atividades para esses jovens - tanto laborais quanto educativas - são escassas. Ainda que garimpadas com tenacidade e interesse pela equipe técnica, bem como pela monitoria, infelizmente, essas não contam com o devido apoio do governo do Estado, que poderia fomentar uma estrutura de rede de atividades, sólida, sistemática e sustentável. Essa escassez de recursos e de possibilidades faz com que esses adolescentes sejam inseridos naquela atividade então disponível, sem que se possa considerar sua experiência de vida, aptidões ou interesses. Disso resulta o apagamento da subjetividade e potencialidade desses sujeitos, e por certo, isso se reflete na apatia dos sujeitos aqui pesquisados, no que tange a sua formação e o seu projeto profissional. É doloroso constatar que esta apatia se dá justamente por aquelas áreas da rede que mais provavelmente os direcionariam para outro estilo de vida.

Também se ressalta a importância do resgate de uma figura paterna mais valorizada e presente para estes internos. E mesmo que ainda hoje exista discordância quanto às conseqüências desta falta na vida desses jovens, há quem defenda que o comportamento anti-social, em qualquer membro da família, é mais provável se o pai é ausente ou não-participativo (Pfiffner, McBurnett \& Rathouz, 2001), e que a ausência paterna pode desencadear um processo de baixa auto-estima e de vazio, além de culpa nesses indivíduos (Ferrari, 1999). Mesmo quem não considera a presença paterna essencial, defende a importância de compensações que se dêem através da interação da mãe com o filho, dos recursos emocionais da mãe, dos fatores ambientais e da família como um todo (Eizirik \& Bergmann, 2004). Portanto, o acompanhamento dessas famílias poderia auxiliar não só no resgate paterno, mas mais do que isso, na melhoria do funcionamento familiar global desses jovens.

Ainda que a Fase-RS seja considerada uma referência em nível nacional, constata-se que muito ainda há por fazer. Neste sentido, a pesquisa pode auxiliar de forma importante no reconhecimento dos problemas e no estabelecimento de novas metas que busquem uma maior arti- 
culação das políticas públicas e, consequentemente, da rede social desses jovens.

\section{Referências}

Caputo, R. K. (2004). Parent religiosity, family processes, and adolescent outcomes. Families in Society, 85(4), 495-510.

Ceolin, L. (2003) A construção dos vínculos afetivos e sociais do adolescente em conflito com a lei. Dissertação de Mestrado nãopublicada, Pontifícia Universidade Católica do Rio Grande do Sul, Porto Alegre, RS.

Dabas, E. (1995). Redes. El lenguaje de los vínculos. Buenos Aires, Argentina: Paidós.

Davis, C., Tang, C., \& Ko, J. (2004). The impact of peer, family and school on delinquency. Internationalizing Social Work Education, 47(4), 489-502.

Diretoria Sócio-Educativa da Fundação Estadual do Bem Estar do Menor/RS. (Ed.). (2002, abr.). Programa de Execução de Medidas Sócio-Educativas de Internação e Semiliberdade PEMSEIS. Por to Alegre, RS: Autor.

Eizirik, M., \& Bergmann, D. S. (2004). Ausência paterna e sua repercussão no desenvolvimento da criança e do adolescente: Um relato de caso. Revista de Psiquiatria do Rio Grande do Sul, 26(3).

Falceto, O. G., Busnello, E. D., \& Bozzetti, E. M. C. (2000). Validação de escalas diagnósticas do funcionamento familiar para utilização em serviços de atenção primária à saúde. Revista Panamericana de Salud Pública/Pan American Journal of Public Health, 7(4), 255-263.

Feinberg, M. E., Riggs, N. R., \& Greenberg, M. T. (2005). Social networks and community prevention coalitions. The Journal of Primary Prevention, 26(4), 279-298.

Ferrari, J. L. (1999). Por que es importante el padre? In J. L. Ferrari (Ed.), Ser padres en el tercer milenio (pp. 91-117). Mendoza, Argentina: Ediciones del Canto Rodado.

Husler, G., Plancherel, B., \& Werlen, E. (2005). Psychosocial predictors of cannabis use in adolescents at risk. Prevention Science, 6(3), 237-244.

Johnson, K. D., Whitbeck, L. B., \& Hoyt, D. R. (2005). Predictors of social network composition among homeless and runaway adolescents. Journal of Adolescence, 28(2), 231-248.

Kaslow, F. (1996). History, rationale and philosophic overview of issues and assumptions. In F. Kaslow (Ed.), Handbook of relational diagnosis and dysfunctional family patterns (pp. 3-28). New York: John Wiley \& Sons.

Laible, D. J., Carlo, G., \& Roesch, S.C. (2004). Pathways to selfesteem in late adolescence: the role of parent and peer atachment, empathy, and social behaviours. Journal of Adolescence, 27(6), 703-716.

Markiewicz, D., Doyle, A. B., \& Brendgen, M. (2001). The quality of adolescents friendships: Associations with mothers interpersonal relationships, attachments to parents and friends, and prosocial behaviors. Journal of Adolescence, 24(4), 429-445.

Meneses, M. P. R. (2004). A construção de redes sócio-familiares de famílias imigrantes hispano-americanas. Tese de Doutorado nãopublicada, Pontifícia Universidade Católica do Rio Grande do Sul, Por to Alegre, RS.

Pfiffner L. J., McBurnett, K., \& Rathouz, P. J. (2001). Father absence and familial antisocial characteristics. Journal of Abnormal Child Psychology, 29(5), 357-367.

Rydelius, P. A. (2001). Antisocial behavior of adolescentes and environment: Need for a multidisciplinary model. Lakartidningen, 98(19), 2313-2316.
Sluzki, C. E. (1996). La red social: frontera de la pratica sistêmica. Barcelona, España: Gedisa.

Stake, R. (2005). Case studies. In N. K. Denzin \& Y. S. Lincoln (Eds.), Handbook of qualitative research (pp. 236-247). London: Sage.

Stouthamer-Loeber, M., Wei, E., Loeber, R., \& Masten, A. S. (2004). Desistance from persistent serious delinquency in the transition to adulthood. Development and Psychopathology, 16, 897-918.

Tucci, A. M., Kerr-Côrrea, F., \& Dalben, I. (2001). Ajuste social em pacientes com transtorno afetivo bipolar, unipolar, distimia e depressão dupla. Revista Brasileira de Psiquiatria, 23(2).

Valdés, M., Serrano, T., Rodríguez, J., Roizblatt, A., Florenzano, R., \& Labra, J. F. (1997). Características del funcionamento familiar que predicen conductas de riesgo en adolescentes y sus famílias. Cuadernos Médico Sociales, 38(4), 14-21.

Wagner, A, \& Féres-Carneiro, T. (2000). O recasamento e a representação gráfica da família. Temas em Psicologia da SBP, $8(1), 11-19$.

Windle, M., \& Mason, W. A. (2004). General and specific predictors of behavioral and emotional problems among adolescents. Journal of Emotional and Behavioral Disorders, 12(1), 49-61. 